\title{
DC/DC Boost Converter Controller
}

\author{
José Ferreira \\ Department of Electric and Computer Engineering, Faculty of Engineering University of Porto, \\ Porto, Portugal (ee11116@fe.up.pt)
}

\begin{abstract}
The DC/DC boost converter is described as a time variant system. State-Space is one of the methods used to approach a time variant system to an invariant time linear system. The present document focuses on a comparative approach of output voltage regulation and system stability and performance. For this document, there were made MatLab tests of PI and PD controllers, with and without fuzzy control.
\end{abstract}

Author Keywords. DC/DC converter, Power Electronics, Fuzzy Control, PI, PD

Type: Research Article

๑े Open Access $\llbracket \mathbf{4}$ Peer Reviewed $@$ (i) CC BY

\section{Introduction}

DC/DC controllers are important in the Power Electronics world, being found in applications with batteries, solar panel systems, cellphones, laptops, etc. Electronic devices are specified with functional and technical requirements, so it is frequent that the input voltage to be different from the output voltage from the battery, or by the power source. The implementation of a DC/DC converter solves this problem. To design the control system of the converter we must model it dynamic response. Also, we must understand how variations in the charge, duty-cycle or input voltage can affect the dynamic answer of the output voltage. Although a lot of strategies to control the duty-cycle have been proposed, in this project it is tested the closed-loop PI controller, Fuzzy PI + PD and an open-loop system to see what controller has the best behavior for this application. The development of the fuzzy controller was based in a theoretic linear controller per Bessel and Hand-Tuning prototypes.

\section{DC/DC converter operation}

The used converter model has only four external components: inductor, switch (MOS transistor), diode and an output capacitor.

Figure 1 illustrates the used model. Although it is possible that the converter can work in discontinuous mode if the inductor fully discharges, the project was made only when the converter is in continuous mode. To complete the model, it was used an output charge R, witch value was changed during the tests.

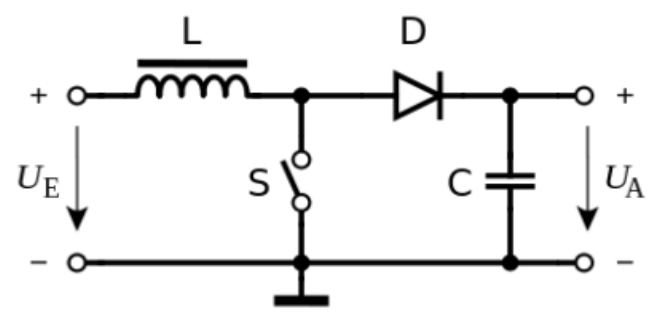

Figure 1: Boost converter circuit 
The transfer function described in Araújo, Leite, and Freitas (2003), is as it follows:

\section{Control-to-input current transfer function:}

$$
\frac{i_{L}(s)}{d_{L}(s)}=\frac{\left(C V_{o}\right) s+2(1-D) I_{L}}{(L C) s^{2}+L / R^{s+(1-D)^{2}}}
$$

Current-to-output transfer function:

$$
\frac{v_{o}(s)}{i_{L}(s)}=\frac{(1-D) V_{o}-\left(L I_{L}\right) s}{\left(C V_{o}\right) s+2(1-D) I_{L}}
$$

\section{Simulation structure}

To facilitate the analyses, the converter was considered ideal, this means, that the switch, capacitor, inductor, and diode don't have any losses.

A. In Figure 2 it is represented the block diagram that models the converter.

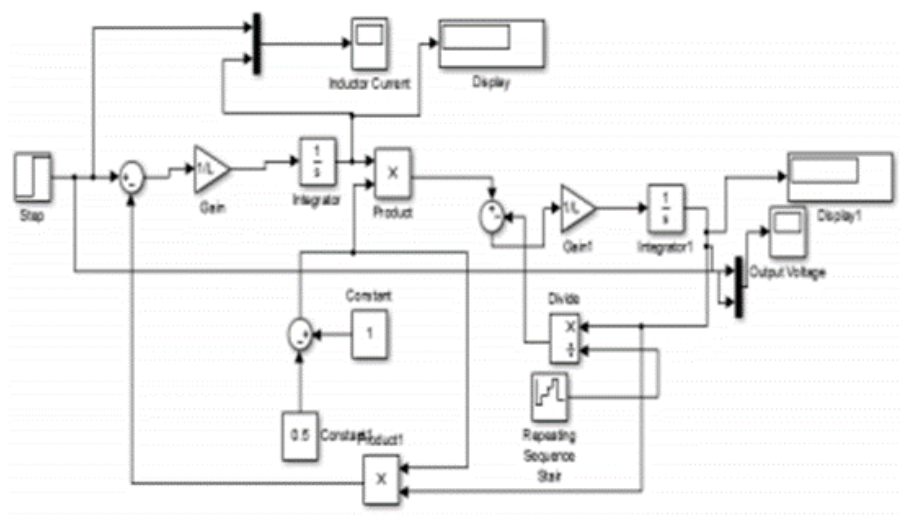

Figure 2: DC/DC converter simulink model

B. In the simulation, there were used the next values for the model:

$$
\begin{aligned}
& L=3.5 * 10^{-3} \\
& C=10 * 10^{-6}
\end{aligned}
$$

C. The duty-cycle varies between 0 and 1 , depending on the required output voltage for a given input voltage.

D. The PI and PD parameters are as it follows:

$$
\begin{gathered}
\mathrm{Kp}=0.028683 ; \\
\mathrm{Ki}=6.3757 ; \\
\mathrm{Kp} 2=4.0215 ; \\
\mathrm{Kd}=0.00011543 ;
\end{gathered}
$$

Figure 3 shows the PI controller with the converter model:

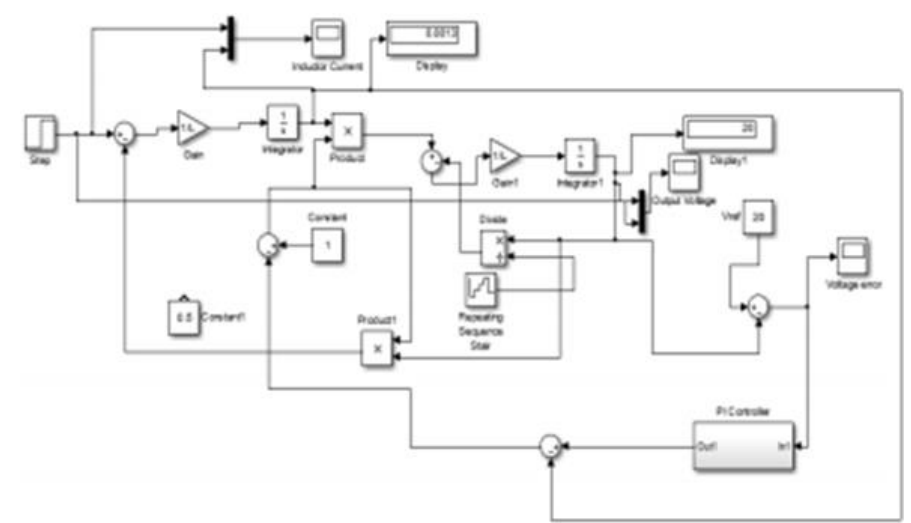

Figure 3: DC/DC + PI Converter Simulink Model 
The PI controller controls the output voltage error by the closed-loop error.

\section{E. Fuzzy Logic}

Fuzzy-Logic is implemented in a system with two inputs: the first receives the output voltage error, comparing it with a reference value, $20 \mathrm{~V}$ in this case; the second calculates the difference between the previous error with the current error, as it is shown in Figures 4 and 5 .

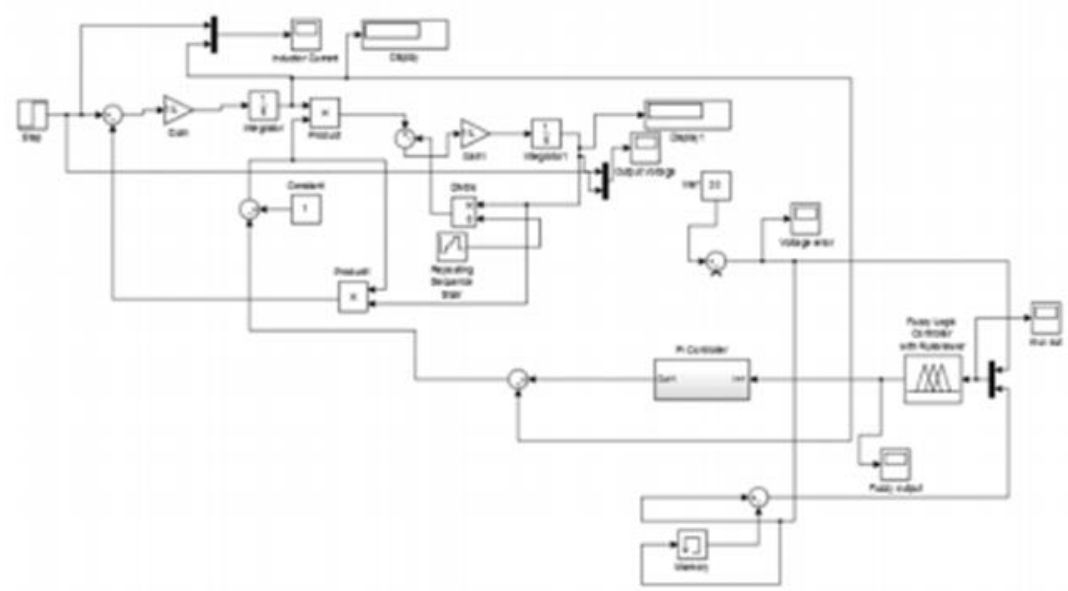

Figure 4: DC/DC Converter + Fuzzy PI Simulink model

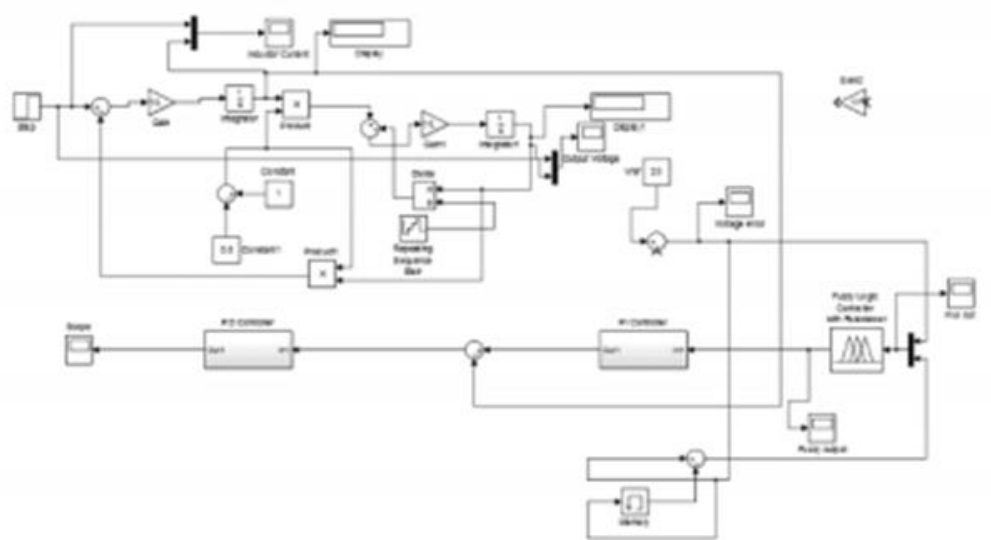

Figure 5: DC/DC Converter + Fuzzy PI + PD Simulink model

The used inputs are the error $(\mathrm{e})$, the change of error $(\mathrm{eC})$. The outputs were made using the followed rules: NN-very negative error; N-negative error; Z-no error; P-positive error; PP-very positive error;

\begin{tabular}{c|ccccc|}
$\mathrm{e}$ & $\mathrm{NN}$ & $\mathrm{N}$ & $\mathrm{Z}$ & $\mathrm{P}$ & $\mathrm{PP}$ \\
\hline $\mathrm{NN}$ & $\mathrm{NN}$ & $\mathrm{NN}$ & $\mathrm{NN}$ & $\mathrm{N}$ & $\mathrm{Z}$ \\
$\mathrm{N}$ & $\mathrm{NN}$ & $\mathrm{NN}$ & $\mathrm{N}$ & $\mathrm{Z}$ & $\mathrm{P}$ \\
$\mathrm{Z}$ & $\mathrm{NN}$ & $\mathrm{N}$ & $\mathrm{Z}$ & $\mathrm{P}$ & $\mathrm{PP}$ \\
$\mathrm{P}$ & $\mathrm{N}$ & $\mathrm{Z}$ & $\mathrm{P}$ & $\mathrm{PP}$ & $\mathrm{PP}$ \\
$\mathrm{PP}$ & $\mathrm{Z}$ & $\mathrm{P}$ & $\mathrm{PP}$ & $\mathrm{PP}$ & $\mathrm{PP}$
\end{tabular}

Table 1: Fuzzy Logic rules table

The objective in the use of the fuzzy-logic was a fast control of great errors and a more moderate voltage control with small errors. For that the next membership functions were created (Figure 6): 

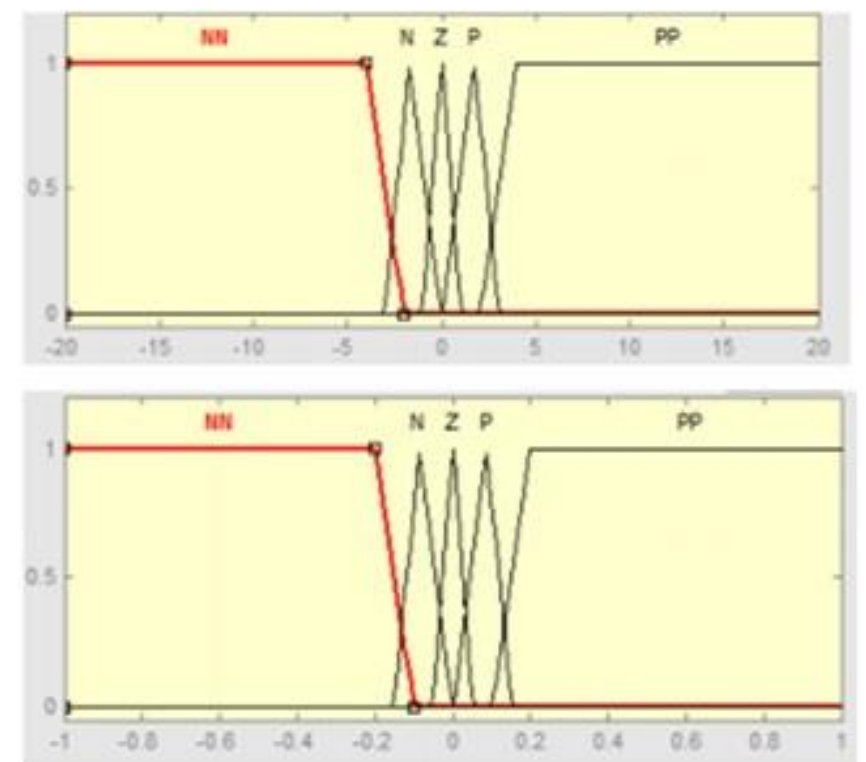

Figure 6: Fuzzy logic membership function: Input, Output

\section{Systems comparison}

Four different approaches were tested using MatLab.

A. Open-Loop

When the converter is used without any control, this has a steady-state error over $25 \%$. This means that this type of converter shouldn't be used without control.

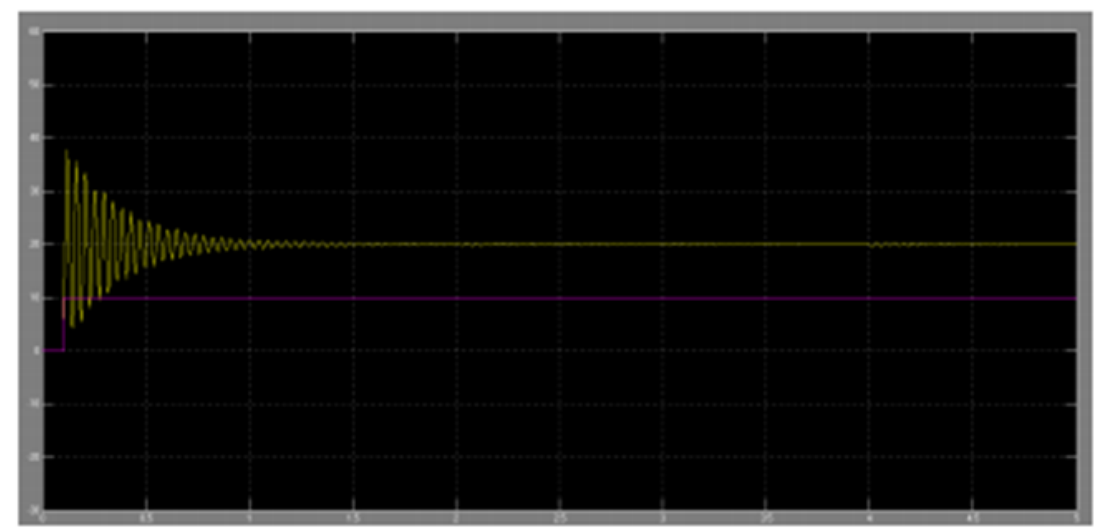

Figure 7: Vout (Open loop)

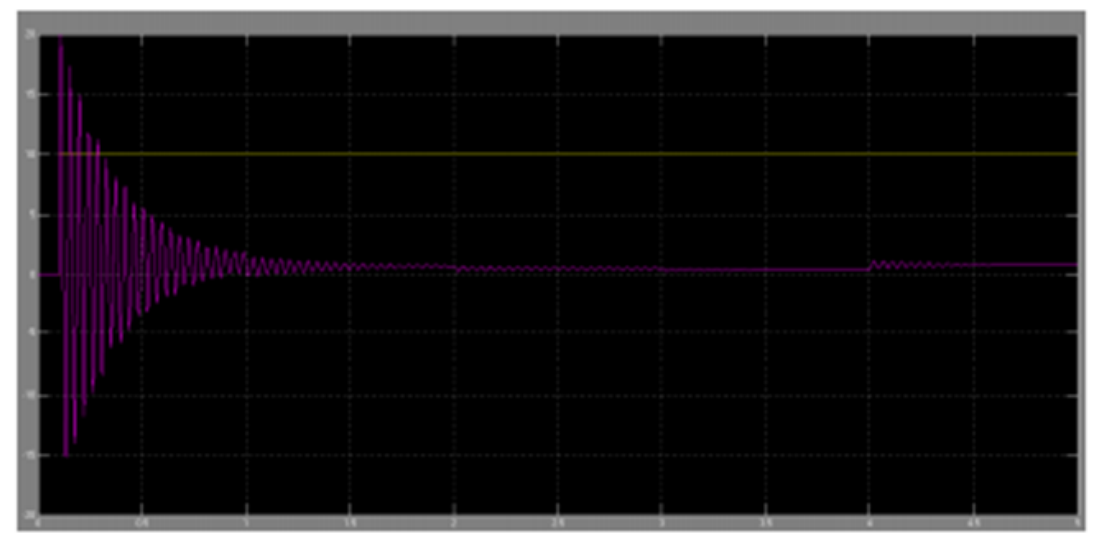

Figure 8: IL (Open loop inductor current)

In both figures ( 7 and 8 ), the value 10 corresponds to the input voltage. The other functions are the output voltage and the current in the inductor. The open-loop system has a too high overshoot and a stabilization time to long. 


\section{B. PI controller}

In a second analysis, a PI controller was implemented. Again, in both graphics the value 10 corresponds to the input voltage.

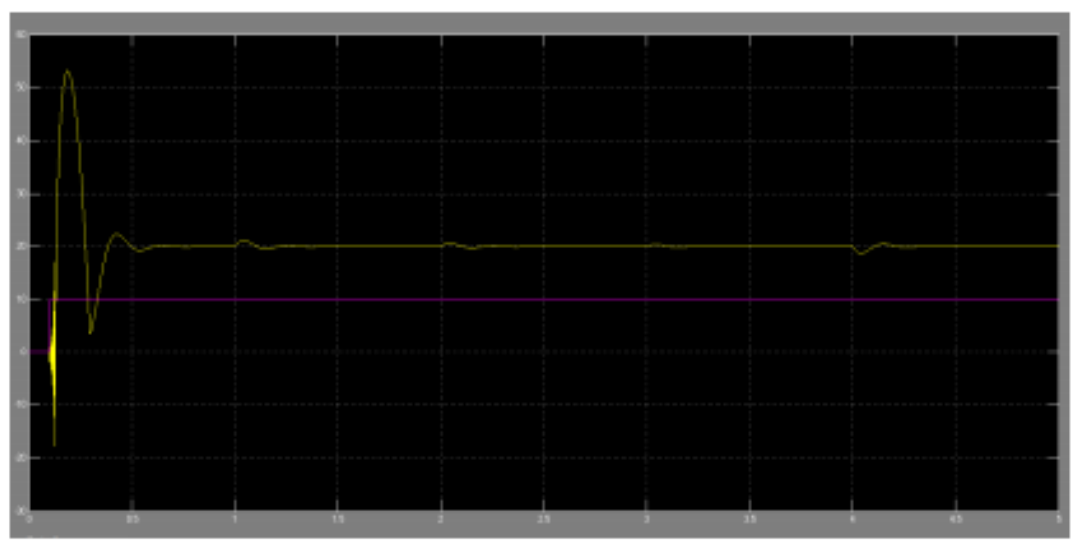

Figure 9: Vout (PI)

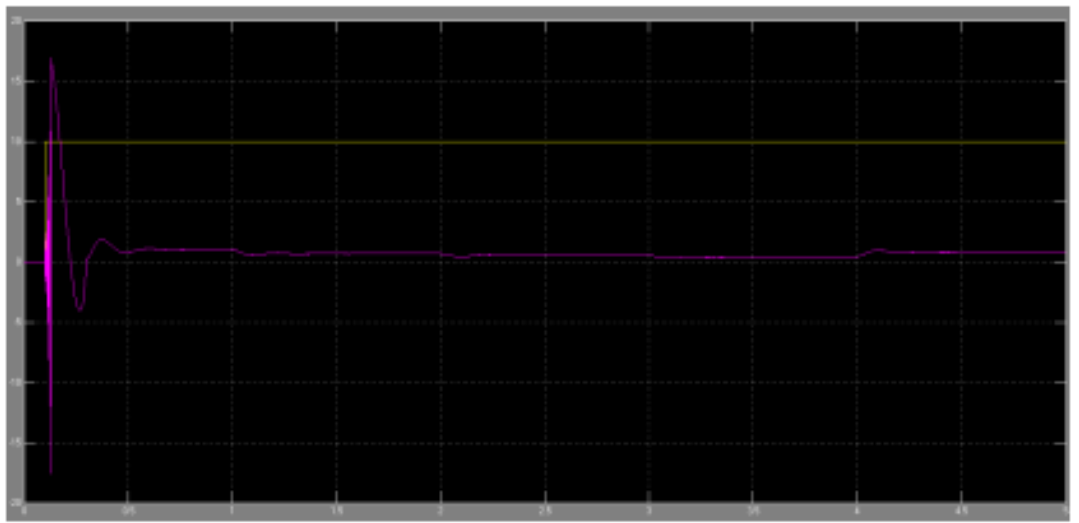

Figure 10: IL (PI)

The PI controller was tested with a variant charge $R=[40,60,100,50] \Omega$, changed each second. As we can see in Figures 9 and 10, there was an improvement in the stabilization time, but the overshoot still has a too high value, in this case, over $100 \%$.

C. PI Fuzzy controller

Using the fuzzy-logic described in the previous chapter, the model was tested with charge and time values equal to the previous test.

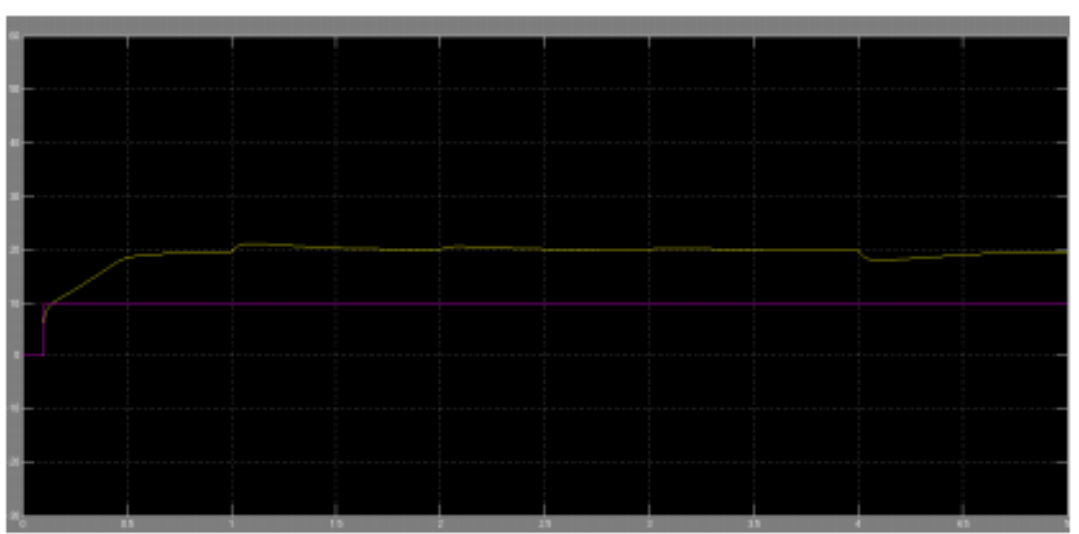

Figure 11: Vout (Fuzzy PI) 


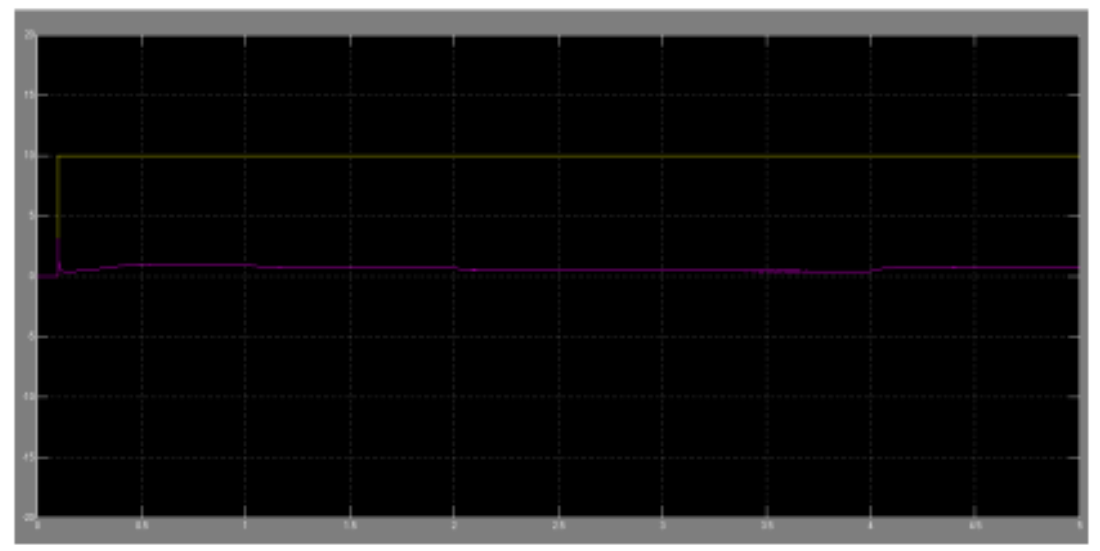

Figure 12: IL (Fuzzy PI)

Comparing the Fuzzy PI model with the PI model, we can see that there was a great improvement both in voltage and current. As we can see in Figures 11 and 12, the maximum overshoot in the voltage is only $15 \%$ of the wanted voltage, and the stabilization time is hort. In the current we get the same improvements.

D. Fuzzy PI+PD controller

Again, the variations in the charge are the same as the previous tests with the same time scale. The PD controller was implemented to verify the behavior of the tested model when the dutycycle varies.

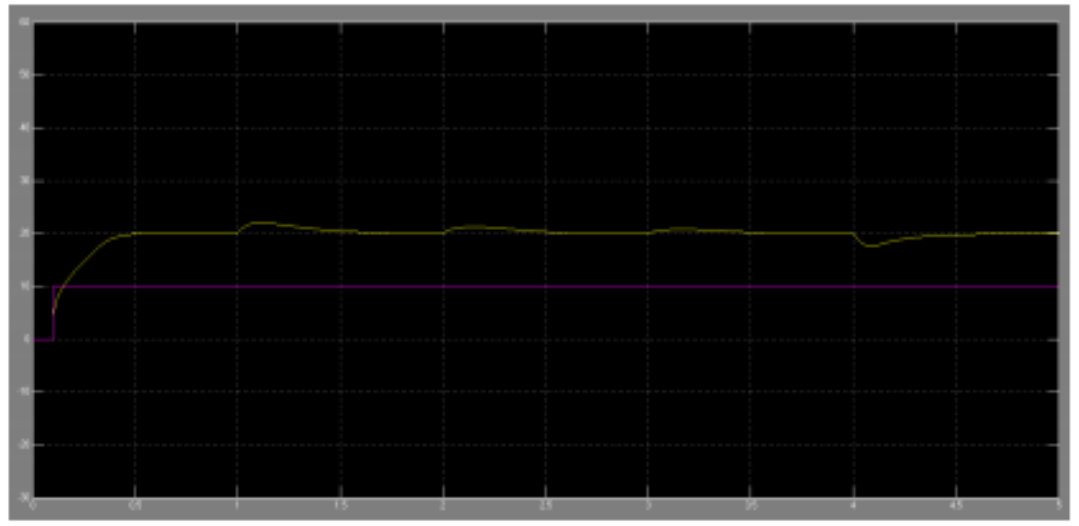

Figure 13: Vout (Fuzzy PI+PD)

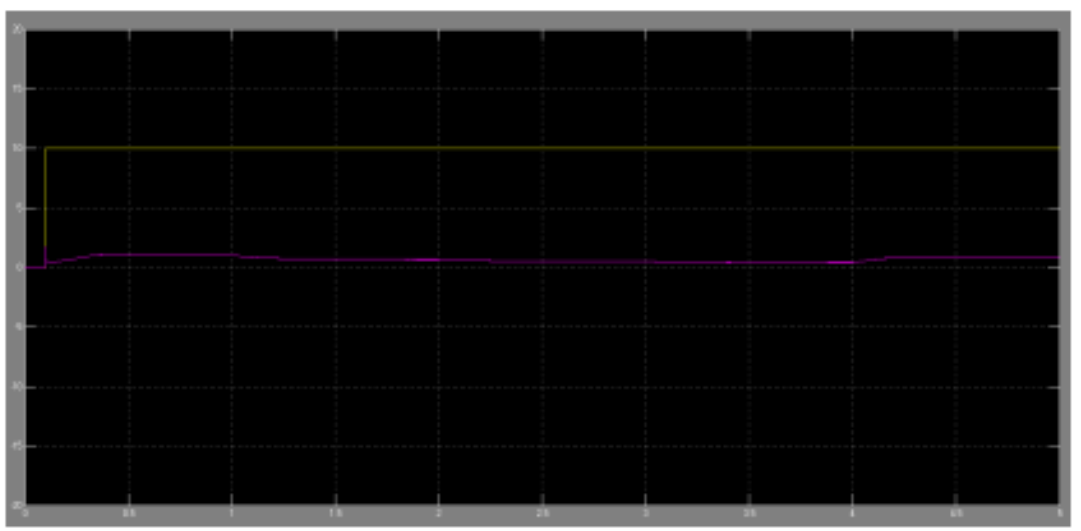

Figure 14: IL (Fuzzy PI+PD)

As we can see, the stabilization time has a small improvement, but the overshot suffers a small aggravation (Figures 13 and 14). 


\section{Conclusion}

The design of a controller is necessary when working with boost DC/DC converters. The PI Fuzzy controller shown a lot of vantages in the direct control of the output error. The Fuzzy $\mathrm{PI}+\mathrm{PD}$ improved the stabilization time of the converter and the steady-state errors were heavily attenuated.

\section{References}

Araújo, R. E., A. V. Leite and D. S. Freitas. 2003. "Sliding mode controllers for the regulation of DC/DC power converters". IFAC Proceedings Volumes 36 (18):407-412. Accessed April 14, 2017. DOI: 10.1016/S1474-6670(17)34702-X. 